\title{
B Lymphoblastic Leukemia/Lymphoma, Not Otherwise Specified
}

National Cancer Institute

\section{Source}

National Cancer Institute. B Lymphoblastic Leukemia/Lymphoma, Not Otherwise

Specified. NCI Thesaurus. Code C80326.

The term refers to precursor lymphoid neoplasms which are composed of B-

lymphoblasts and characterized by the absence of recurrent genetic abnormalities. 